\title{
Primary Vulvar Ewing Sarcoma in a 30-Year-Old Woman: A Case Report
}

\author{
Fatoumata Matokoma Sidibe1, Hajar Ouahbi1, Rajae Kanab1, Layla Tahiri², \\ Fatim Zhara El Mrabet ${ }^{1}$, Samia Arifi' ${ }^{1}$, Hind El Fatemi ${ }^{2}$, Nawfel Mellas ${ }^{1}$ \\ ${ }^{1}$ Medical Oncology Department, HASSAN II University Hospital, Fez, Morocco \\ ${ }^{2}$ Pathology Department, HASSAN II University Hospital, Fez, Morocco \\ Email: fatsi_2@hotmail.com
}

How to cite this paper: Sidibe, F.M., Ouahbi, H., Kanab, R., Tahiri, L., El Mrabet, F.Z., Arifi, S., El Fatemi, H. and Mellas, N. (2018) Primary Vulvar Ewing Sarcoma in a 30-Year-Old Woman: A Case Report. Case Reports in Clinical Medicine, 7, 241-248. https://doi.org/10.4236/crcm.2018.73022

Received: December 17, 2017

Accepted: March 18, 2018

Published: March 21, 2018

Copyright $\odot 2018$ by authors and Scientific Research Publishing Inc. This work is licensed under the Creative Commons Attribution International License (CC BY 4.0).

http://creativecommons.org/licenses/by/4.0/

\begin{abstract}
Primary Ewing sarcoma (ES) and primitive neuroectodermal tumor (PNET) are considered as Ewing sarcoma family of tumors (ESFT), characterized by chromosomal translocation $\mathrm{t}(11 ; 22)$ (q24; q12) leading to a chimeric transcript EWS-FLI1 in $85 \%$ of cases. It typically involves the soft tissues of the chest wall, pelvis, paravertebral region, abdominal wall, retroperitoneal region and extremities in children, adolescents and young adults. It rarely occurs in the female genital tract. We report an extremely rare case of advanced vulvar Ewing sarcoma/PNET of the vulva confirmed by Fluorescence In Situ Hybridization (FISH) in a 30-year-old woman. The patient was treated by $6 \mathrm{cy}$ cles of chemotherapy followed by radiotherapy with favourable outcome.
\end{abstract}

\section{Keywords}

Ewing Sarcoma/Primitive Neuroectodermal Tumor, Vulva, Advanced Disease, Multimodal Treatment

\section{Introduction}

Primary Ewing sarcoma (ES) and primitive neuroectodermal tumor (PNET) are considered Ewing sarcoma family of tumors (ESFT), characterized by chromosomal translocation $\mathrm{t}(11 ; 22)$ (q24; q12) leading to a chimeric transcript EWSFLI1 (a member of ETS gene) in $85 \%$ of cases [1]. In 5\% - 10\% of cases EWS gene is fused with other members of Erythroblast Transformation-Specific (ETS) gene (ERG, ETV 1, ETV 4 and FEV). ES/PNET is an aggressive malignant round cell tumor yet chemosensitive [2]. They commonly affect bones and especially diaphysis of longs bones. Extraskeletal ES/PNET can arise anywhere in the body, including soft tissue, skin and visceral organs [3]. However, they have been 
rarely found in the female genital tract, with occasional reports of tumors arising in the vulva, vagina, cervix, uterine corpus, broad ligament, and ovary [4].

Here, we present a case of 30-year-old woman with a confirmed ES arising in the vulva and we report a systematic review of the published literature regarding primary vulvar ES.

\section{Case Report}

A 30-year-old woman, with a history of two spontaneous vaginal deliveries at term, presented with progressive left vulvar swelling since 10 months.

Physical examination showed a "non-cystic", painless, mobile lesion, $15 \times 12$ $\mathrm{cm}$ in size. She had no further symptoms or lesions. Abdominal and pelvic computed tomography (CT) showed a mixed mass in the left vulva, $146 \mathrm{~mm} \times$ $78 \mathrm{~mm}$ in size, which invades by contiguity the vagina, anal margin, low rectum, obturator muscle, ischion and pubis (Figure 1).

Blood test and chest CT were normal and bone scan showed ischion and pubis fixation. The extensive surgical resection of the lesion was not recommended due to patient's young age, histological type, size and extension of the vulvar tumor. She underwent core biopsy.

Microscopic sections with hematoxylin and eosin staining (HES) displayed a malignant round cell tumor with monomorphic cells arranged in a diffuse manner, containing fine chromatin, scanty indistinct cytoplasm, and inconspicuous nucleoli (Figure 2).

Immunohistochemestry showed diffuse cytoplasmic membranous staining with CD99, suggesting ESFT diagnosis (Figure 3). In parallel, muscle markers

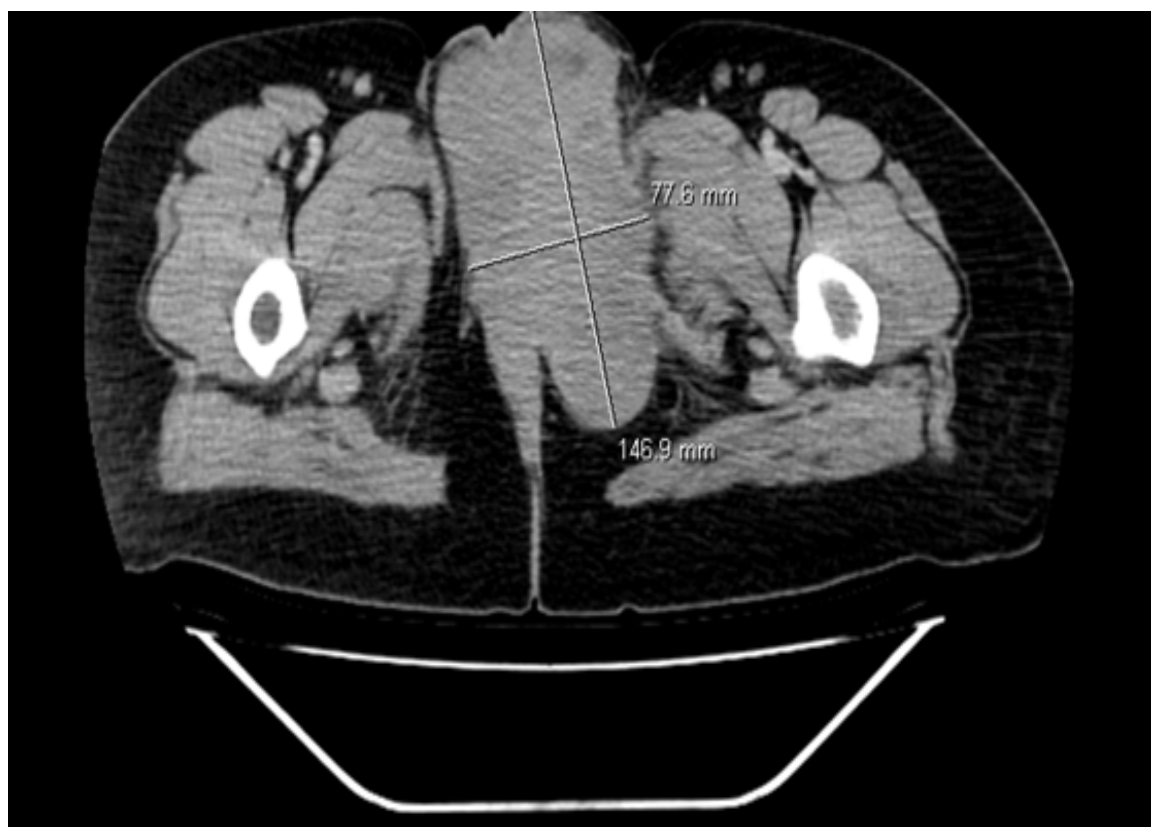

Figure 1. Initial computed tomography scan of the pelvic showing a $147 \mathrm{~mm} \times 78 \mathrm{~mm}$ sized mixed mass lesion in the left vulva with locally extension to the vaginal, anal canal, low rectum, obturator muscle, ischion and pubis. 


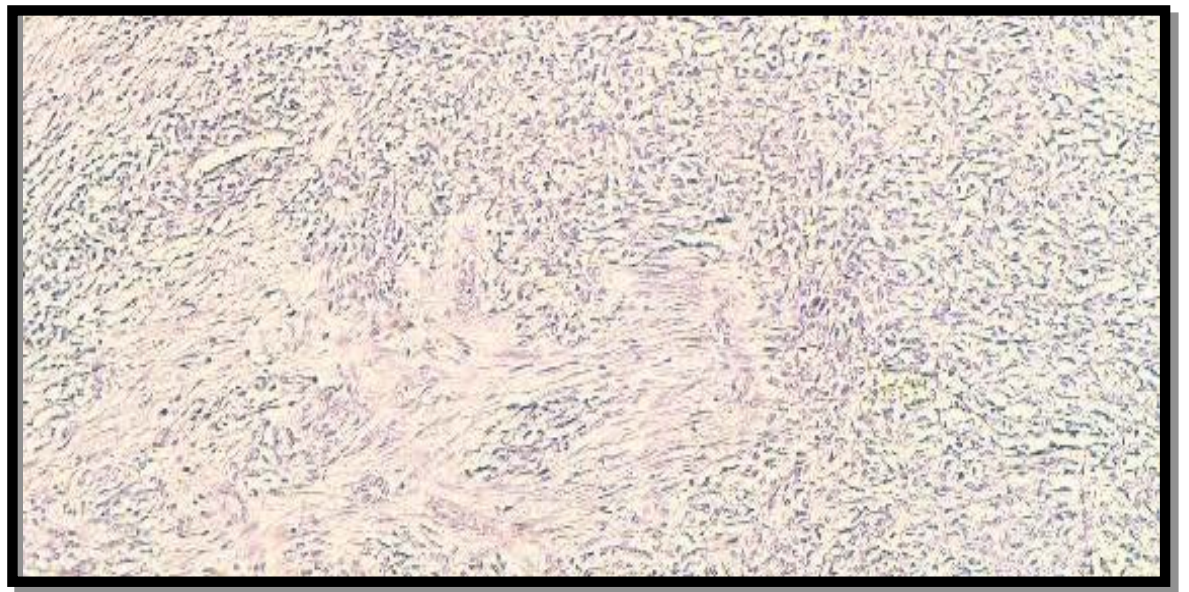

Figure 2. Microscopically (Hematoxylin and eosin staining $\times 20$ ) showing monomorphic small round cells arranged in a diffuse manner, containing fine chromatin, scanty indistinct cytoplasm, and inconspicuous nucleoli.

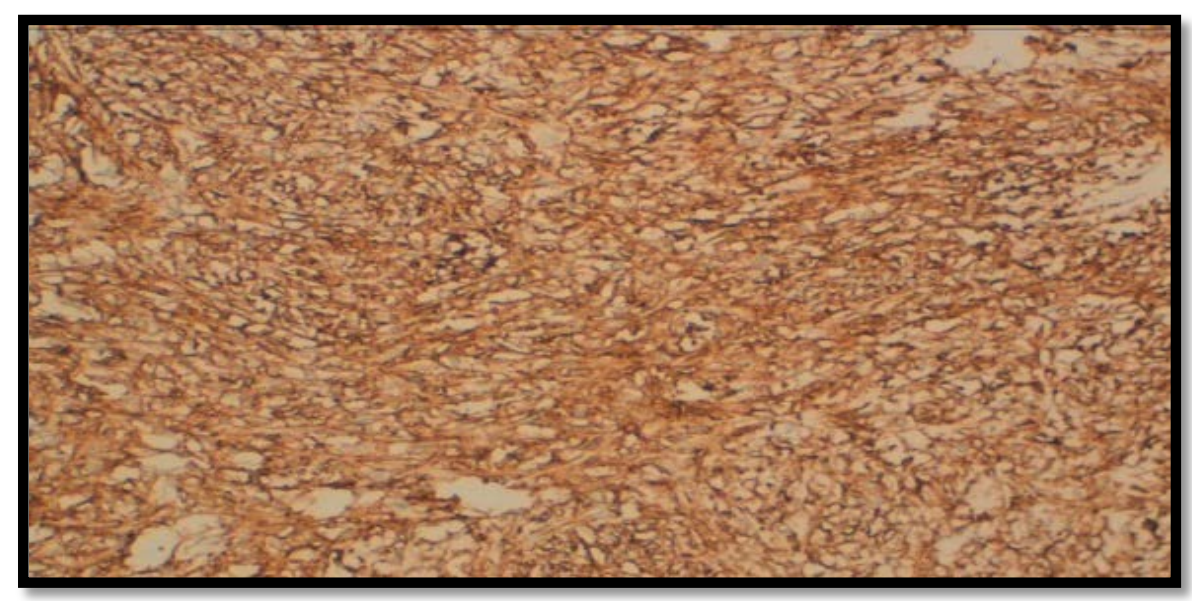

Figure 3. Immunohistochemical study usinganti-CD99 monocal antibody (EPR3097Y) and showing cytoplasmic membranous diffuse staining with CD99

(desmin, myogenin), CD45, the neuroendocrine markers (Synaptophysine andchromogranin A), epithelial markers (EMA, CKAE1/AE3), and Bcl2 were negative.

Finally, in molecular cytogenetic analyse, fluorescent in-situ hybridization (FISH) showed $100 \%$ rearrangement of EWSR1 on chromosome 21 of 100 analyzed nuclei, confirming the diagnosis of primary vulvar ES/PNET.

Patient received combination chemotherapy with Doxorubicine $20 \mathrm{mg} / \mathrm{m}^{2} /$ Day (D), D1-3, Vincristine $2 \mathrm{mg}$ D1, ifosfamide $2000 \mathrm{mg} / \mathrm{m}^{2} / \mathrm{D}, \mathrm{D} 1-\mathrm{D} 3$ and uromitexan every three weeks. After six cycles, CT scan evaluation showed a $46 \%$ reduction of vulvar mass according to RECIST (Response Evaluation Criteria In Solid Tumor) 1.1 criteria [5].

Extensive surgical resection of the residual lesion was not recommended in the multidisciplinary consultation meeting because of high $\mathrm{R} 1$ resection risk. External pelvic radiation therapy was delivered at a dose of $46 \mathrm{~Gy}$. Then, patient 
receives monthly biphosphonate for the local bone extension. We regularly followed her with quarterly physical examination, blood test and chest, abdominal and pelvic CT scan. Since then, she had a stable disease with persistent mass of $41 \times 30 \mathrm{~mm}$ in size after 22 months of follow up.

\section{Discussion}

Ewing sarcoma (ES) and primitive neuroectodermal tumor (PNET) family were regarded as distinct in the past. Recently, studies have shown that the small round-cell tumor seen in both tumor types share common phenotypic and molecular features, supporting the concept of a single tumor category [6]. ES/PNET are characterized by the fusion of the ESW gene on chromosome 22q12 with various members of the Erythroblast Transformation-Specific (ETS) gene family (FLI1, ERG, ETV1, ETV4 and FEV). The fusion with ESW and FLI1 on chromosome 11 and corresponding chromosomal translocation $\mathrm{t}(11 ; 22)(\mathrm{q} 24 ; \mathrm{q} 12)$ is present in $85 \%$ of patients with ES/PNET [7].

ES/PNET are an uncommon high-grade malignant neoplasm that may affect both skeletal and extraskeletal sites. Extraskeletal Ewing sarcoma (EES) is an unusual aggressive tumor with poor prognosis. It involves soft tissues of the chest wall, extremities, paravertebral and retroperitoneal regions, pelvis and abdomen, skin, visceral organs, head and neck [8] [9] [10] [11] but rarely occurs in the female genital tract. In this last location, EES has extremely low incidence in the vulva with nearly 25 such documented cases in the literature (Table 1). Here, we report the twenty sixth case of primary vulvar EES in a 30-year-old woman who was treated with multiagent chemotherapy and definitive radiation. We also summarized the clinicopathologic details and management of previously described cases of vulvar EES together with our case.

Vulvar EES occurs in young women and women of reproductive age (as the case of our patient), median age is 20 years and mean age is 24 years ranging from 10 - 52 years (Table 1). In general, patients present with painless vulvar swelling.

The main morphology of ES is usually a lobulated architecture with solid aggregate of cells, forming sometimes rosettes [12]. Histologically, monomorphic population of small round blue cells, not well defined borders, scanty cytoplasm glycogen and high mitotic index are typical features of ES. In immunohistochemistry, the overexpression of CD99, a cell surface glycoprotein encoded by the MIC2 gene and positivity of Fli-1 in a nuclear pattern are other characteristics of ES [13] [14] [15] and have been demonstrated to be extremely useful in positive diagnosis [13]. CD99 antigen is a very sensitive marker but lacks specificity while Fli-1 is less sensitive but more specific than CD99 [3] [7]. Finally, molecular cytogenetic analysis (Reverse Transcriptase polymerase chain reaction, RT-PCR or fluorescence in situ hybridization, FISH) can detect the hybrid transcripts EWS/Fli-1, EWS/ERG and rearrangement of EWSR1 on chromosome $21[3]$ [11]. 
Table 1. Clinicopathologic features of reported cases of vulvar ES/PNET.

\begin{tabular}{|c|c|c|c|c|c|c|c|}
\hline Case & Study & Age $(y)$ & Size $(\mathrm{cm})$ & Treatment & Immunohistochemistry & Molecular tests & Follow-up \\
\hline $1^{*}$ & Vang et al. [4] & 28,15 & $0.9,20$ & $\mathrm{~S}+\mathrm{CT}+\mathrm{RT}$ & CD99+ (2 cases $)$ & $\begin{array}{c}\text { EWS/FLI1+ } \\
(2 \text { cases })\end{array}$ & $\begin{array}{c}\text { FOD at } 18 \mathrm{M} \\
\text { FOD } 19 \mathrm{M}\end{array}$ \\
\hline 2 & Scherr et al. [15] & 10 & 6.5 & NK & CD99+ & No & NA \\
\hline 3 & Habib et al. [16] & 23 & NK & NK & No & No & NA \\
\hline 4 & Nirenberg et al. [17] & 20 & 12 & $\mathrm{~S}+\mathrm{CT}+\mathrm{RT}$ & CD99- & No & DOD $10 \mathrm{M}$ \\
\hline 5 & Lazure et al. [18] & 15 & 20 & $\mathrm{~S}+\mathrm{CT}$ & CDD99+ & EWS/FLI1+ & FOD $7 \mathrm{M}$ \\
\hline 6 & Moodley et al. [19] & 26 & 5 & $\mathrm{CT}+\mathrm{RT}$ & No & No & NK \\
\hline 7 & Parede et al. [20] & 29 & 5 & $\mathrm{~S}+\mathrm{CT}+\mathrm{RT}$ & No & No & FOD $8 \mathrm{M}$ \\
\hline $8^{* *}$ & McCluggage et al. [21] & $19,40,20$ & $4,3,6.5$ & $\begin{array}{c}\mathrm{S}+\mathrm{CT} \\
\mathrm{S}+\mathrm{CT} \\
\mathrm{S} \text { of lung } \mathrm{M}+ \\
\mathrm{S}+\mathrm{CT}+\mathrm{RT} \\
\mathrm{S}+\mathrm{CT}\end{array}$ & $\begin{array}{l}\text { CD99+, FLI1- } \\
\text { CD99+ FLI1+ } \\
\text { CD99+ FLI1+ } \\
\text { CD99+ ( } 2 \text { cases })\end{array}$ & $\begin{array}{c}\text { RTPCR, FISH- } \\
\text { FISH+ } \\
\text { FISH+ } \\
\text { EWS/FLI1+ } \\
\text { EWS/FLI1- }\end{array}$ & $\begin{array}{c}\text { NA } \\
\text { FOD 12M DOD (Lung M+) } \\
\text { FOD } 84 \mathrm{M} \\
\text { FOD } 61 \mathrm{M}\end{array}$ \\
\hline 10 & Boldorini et al. [23] & 52 & 4 & $\mathrm{~S}+\mathrm{CT}+\mathrm{RT}$ & CD99+ & EWSR1 R + & FOD $12 \mathrm{M}$ \\
\hline 11 & Halil et al. [24] & 14 & NK & $\mathrm{S}+\mathrm{CT}+\mathrm{RT}$ & No & No & DOD $9 \mathrm{M}$ (lung $\mathrm{M}+$ ) \\
\hline 12 & Anastasiades et al. [3] & 28 & 3 & $\mathrm{~S}+\mathrm{CT}+\mathrm{RT}$ & CD99+ & No & DOD $12 \mathrm{M}$ \\
\hline 13 & Kelling et al. [25] & 18 & NK & S & NK & NK & NK \\
\hline 14 & Che et al. [13] & 37 & NK & $\mathrm{S}+\mathrm{CT}$. Lung $\mathrm{M}+$ & CD99+, FLI1+ & No & AWD $12 \mathrm{M}$ \\
\hline $15^{\star}$ & Xiao et al. [26] & 20,36 & NK & No & $\begin{array}{l}\text { CD99+ in } 2 \text { cases } \\
\text { (Biopsy) }\end{array}$ & No & $\begin{array}{l}\text { Bone and lung } \mathrm{M}+, \mathrm{DOD} . \\
\text { Lung } \mathrm{M}+, \mathrm{DOD}\end{array}$ \\
\hline 16 & Rekhi et al. [2] & 10 & 8 & $\mathrm{~S}+\mathrm{CT}$ & CD99+, Fli1+ & $\begin{array}{c}\text { ESW/FLI1-/EWS } \\
\text { R1 R+ }\end{array}$ & $\begin{array}{l}\text { CR. Recurrence with new } \\
\text { lung M+. AWD } 18 \mathrm{M}\end{array}$ \\
\hline 17 & Tunitsky et al. [27] & 15 & 5 & $\mathrm{~S}+\mathrm{CT}$ & NK & NK & FOD $20 \mathrm{M}$ \\
\hline 18 & Dadhwal et al. [28] & 20 & 20 & NK & NK & NK & DOD (metastatic disease) \\
\hline 19 & Fong et al. [14] & 17 & NK & NK & CD99+, FLI1+ & EWS/FLI1+ & NK \\
\hline 20 & Yang et al. [29] & 20 & NK & No & CD99+ & RT-PCR+ & DOD (bone and lung $\mathrm{M}+$ ) \\
\hline 21 & Present case & 30 & 16 & $\mathrm{CT}+\mathrm{RT}$ & CD99+ & EWSR1 R+ & FOD $22 \mathrm{M}$ \\
\hline
\end{tabular}

CT: chemotherapy, RT: Radiotherapy, S: surgery, NK: not known, NA: not available, FOD: Free of disease, DOD: died of disease, AWD: alive of disease, RT-PCR: Reverse transcriptase polymerase chain reaction, FISH: Fluorescence in situ hybridization, EWSR1 R+: EWSR1 rearrangement positive, M: month, Y: Years, M+: metastases, ${ }^{*}: 2$ cases, ${ }^{* *}: 3$ cases.

These main morphological, histological, immunohistochemical and cytogenetic features were all found in our reported case. In parallel, we excluded the differential diagnosis in immunohistochemistry staining as lymphoblastic lymphoma, small cell neuroendocrine carcinoma, rhabdomyosarcoma, carcinosarcoma and epithelial carcinoma.

Treatment of vulvar EES includes complete surgical excision of the lesion, chemotherapy, and, occasionally, radiation therapy (Table 1).

Only one patient in the reported case (case 6) received chemotherapy follow by radiation therapy without surgery, as in our case. She developed chest metastases within a short period of time and subsequently died.

In our case, despite a radiologic downstaging according to the RECIST criteria 
1.1 [5], surgery was not attempted due to initial very advanced disease and the high risk of R1 resection (microscopic margin invasion).

Except in two cases of Cetiner and al, which had long follow-up (more than 4 and 7 years), others reported cases have been limited (ranging 7 - 20 months in 12 cases or died at short time in 4) or no long term follow up data (six cases). Thus, the best way of treating vulvar EES is difficult to predict but it appears clear that multimodal treatment is better.

Our patient received chemotherapy, and then radiotherapy. About 22 months after diagnosis, she is alive and no evidence of progressive disease.

\section{Conclusions}

Primary vulvar ES/PNET is a rare malignancy that requires early diagnosis and treatment. Multimodal treatment including surgery, chemotherapy, and/or radiotherapy is required.

Because of the rare reported cases in literature, it is difficult to draw any conclusion about tumor behaviour, epidemiology or standard management. Studies of more cases of primary vulvar ES/PNET with longer follow-up periods are needed to clarify its clinicopathologic features and its treatment.

\section{Disclosure}

No author has any potential conflict of interest.

\section{References}

[1] Aurias, A., Rimbaut, C., Buffe, D., Dubousset, J. and Mazabraud, A. (1983) Translocation of Chromosome 22 in Ewing's Sarcoma. Comptes Rendus des Seances de I'Academie des Sciences-Serie III, 296, 1105-1107.

[2] Rekhi, B., Chinnaswamy, G., Vora, T., Shah, S. and Rangarajan, V. (2015) Primary Ewing Sarcoma of Vulva, Confirmed with Molecular Cytogenetic Analysis: A Rare Case Report with Diagnostic and Treatment Implications. Indian Journal of Pathology \& Microbiology, 58, 341-344. https://doi.org/10.4103/0377-4929.162869

[3] Anastasiades, E.N., El Abiad, S.A. and Chouairy, J.C. (2012) Ewing Sarcoma/Primitive Neuroectodermal Tumor (PNET) of the Vulva. Case Report and Review of the Literature. Le Journal Medical Libanais, 60, 113-116.

[4] Vang, R., Taubenberger, J.K., Mannion, C.M., Bijwaard, K., Malpica, A., Ordonez, N.G., Tavassoli, F.A. and Silver, S.A. (2000) Primary Vulvar and Vaginal Extraosseous Ewing's Sarcoma/Peripheral Neuroectodermal Tumor: Diagnostic Confirmation with CD99 Immunostaining and Reverse Transcriptase-Polymerase Chain Reaction. International Journal of Gynecological Pathology, 19, 103-109. https://doi.org/10.1097/00004347-200004000-00002

[5] Eisenhauer, E.A., Therasse, P., Bogaerts, J., Schwartz, L.H., Sargent, D., Ford, R., Dancey, J., Arbuck, S., Gwyther, S., Mooney, M., Rubinstein, L., Shankar, L., Dodd, L., Kaplan, R., Lacombe, D. and Verweij, J. (2009) New Response Evaluation criTeria in Solid Tumours: Revised RECIST Guideline (Version 1.1). European Journal of Cancer, 45, 228-247. https://doi.org/10.1016/j.ejca.2008.10.026

[6] Yip, C.M., Hsu, S.S., Chang, N.J., Wang, J.S., Liao, W.C., Chen, J.Y., Liu, S.H. and Chen, C.H. (2009) Primary Vaginal Extraosseous Ewing Sarcoma/Primitive Neuroec- 
todermal Tumor with Cranial Metastasis. Journal of the Chinese Medical Association, 72, 332-335. https://doi.org/10.1016/S1726-4901(09)70381-8

[7] Folpe, A.L., Hill, C.E., Parham, D.M., O’Shea, P.A. and Weiss, S.W. (2000) Immunohistochemical Detection of FLI-1 Protein Expression: A Study of 132 Round Cell Tumors with Emphasis on CD99-Positive Mimics of Ewing's Sarcoma/Primitive Neuroectodermal Tumor. The American Journal of Surgical Pathology, 24, 1657-1662. https://doi.org/10.1097/00000478-200012000-00010

[8] Dagher, R., Pham, T.A., Sorbara, L., Kumar, S., Long, L., Bernstein, D., Mackall, C., Raffeld, M., Tsokos, M. and Helman, L. (2001) Molecular Confirmation of Ewing Sarcoma. Journal of Pediatric Hematology/Oncology, 23, 221-224. https://doi.org/10.1097/00043426-200105000-00009

[9] Carvajal, R. and Meyers, P. (2005) Ewing's Sarcoma and Primitive Neuroectodermal Family of Tumors. Hematology/Oncology Clinics of North America, 19, 501-525. https://doi.org/10.1016/j.hoc.2005.03.004

[10] Gaona-Luviano, P., Unda-Franco, E., González-Jara, L., Romero, P. and MedinaFranco, H. (2003) Primitive Neuroectodermal Tumor of the Vagina. Gynecologic Oncology, 91, 456-458. https://doi.org/10.1016/S0090-8258(03)00500-6

[11] Khoury, J.D. (2005) Ewing Sarcoma Family of Tumors. Advances in Anatomic Pathology, 12, 212-220. https://doi.org/10.1097/01.pap.0000175114.55541.52

[12] Chokoeva, A.A., Tchernev, G., Cardoso, J.C., Patterson, J.W., Dechev, I., Valkanov, S., Zanardelli, M., Lotti, T. and Wollina, U. (2015) Vulvar Sarcomas: Short Guideline for Histopathological Recognition and Clinical Management. Part 2. International Journal of Immunopathology and Pharmacology, 28, 178-186. https://doi.org/10.1177/0394632015575977

[13] Che, S.M., Cao, P.L., Chen, H.W., Liu, Z. and Meng, D. (2013) Primary Ewing's Sarcoma of Vulva: A Case Report and a Review of the Literature. Journal of Obstetrics and Gynaecology Research, 39, 746-749. https://doi.org/10.1111/j.1447-0756.2012.02019.x

[14] Fong, Y.E., López-Terrada, D. and Zhai, Q.J. (2008) Primary Ewing Sarcoma/ Peripheral Primitive Neuroectodermal Tumor of the Vulva. Human Pathology, 39, 1535-1539. https://doi.org/10.1016/j.humpath.2008.01.013

[15] Scherr, G.R., d'Ablaing 3rd, G. and Ouzounian, J.G. (1994) Peripheral Primitive Neuroectodermal Tumor of the Vulva. Gynecol Oncol, 54, 254-258. https://doi.org/10.1006/gyno.1994.1204

[16] Habib, K., Finet, J.F., Plantier, F., et al. (1992) A Rare Lesion of the Vulva. Archives d'Anatomie et de Cytologie Pathologiques, 40, 158-159.

[17] Nirenberg, A., Ostör, A.G., Slavin, J., et al. (1995) Primary Vulvar Sarcomas. International Journal of Gynecological Pathology, 14, 55-62. https://doi.org/10.1097/00004347-199501000-00010

[18] Lazure, T., Alsamad, I.A., Meuric, S., et al. (2001) Primary Uterine and Vulvar Ewing's Sarcoma/Peripheral Neuroectodermal Tumors in Children: Two Unusual Locations. Annales de Pathologie, 21, 263-266.

[19] Moodley, M. and Jordaan, A. (2005) Ewing's Sarcoma of the Vulva. A Case Report. International Journal of Gynecological Cancer, 15, 117-118. https://doi.org/10.1111/j.1525-1438.2005.00330.x

[20] Paredes, E., Duarte, A., Couceiro, A., et al. (1995) A Peripheral Neuroectodermal Tumor of the Vulva. Acta Medica Portuguesa, 8, 161-163.

[21] McCluggage, W.G., Sumathi, V.P., Nucci, M.R., Hirsch, M., Dal Cin, P., Wells, M., 
Flanagan, A.M. and Fisher, C. (2007) Ewing Family of Tumours Involving the Vulva and Vagina: Report of a Series of Four Cases. Journal of Clinical Pathology, 60, 674-680. https://doi.org/10.1136/jcp.2006.040931

[22] Cetiner, H., Kir, G., Gelmann, E.P., et al. (2009) Primary Vulvar Ewing Sarcoma/Primitive Neuroectodermal Tumor. A Report of 2 Cases and Review of the Literature. International Journal of Gynecological Cancer, 19, 1131-1136. https://doi.org/10.1111/IGC.0b013e3181acae33

[23] Boldorini, R., Riboni, F., Cristina, S., Allegrini, S., Valentini, S., Muscara, M. and Ruspa, G. (2010) Primary Vulvar Ewing's Sarcoma/Primitive Neuroectodermal Tumor in a Post-Menopausal Woman: A Case Report. Pathology, Research and Practice, 206, 476-479.

[24] Halil, S., Kucuk, M., Arvas, M., Aydin, O. and Calay, Z.Z. (2011) Peripheral Primitive Neuroectodermal Tumor (PNET) of the Vulva: A Case Report. European Journal of Gynaecological Oncology, 32, 117-118.

[25] Kelling, K., Noack, F., Altgassen, C., Kujath, P., Bohlmann, M.K. and Hoellen, F. (2012) Primary Metastasized Extraskeletal Ewing Sarcoma of the Vulva: Report of a Case and Review of the Literature. Archives of Gynecology and Obstetrics, 285, 785-789. https://doi.org/10.1007/s00404-011-2011-x

[26] Xiao, C., Zhao, J., Guo, P., Wang, D., Zhao, D., Ren, T., et al. (2014) Clinical Analysis of Primary Primitive Neuroectodermal Tumors in the Female Genital Tract. International Journal of Gynecological Cancer, 24, 404-409. https://doi.org/10.1097/IGC.0000000000000082

[27] Tunitsky-Bitton, E., Uy-Khroh, M.J., Michener, C. and Tarr, M.E. (2015) Primary Ewing Sarcomapresenting a Vulvar Mass in an Adolescent: Case Report and Review of Literature. Journal of Pediatric and Adolescent Gynecology, 28, e179-e183. https://doi.org/10.1016/j.jpag.2015.04.004

[28] Dadhwal, V., Bahadur, A., Gupta, R., Bansal, S. and Mittal, S. (2010) Peripheral Neuroectodermal Tumor of the Vulva: A Case Report. Journal of Lower Genital Tract Disease, 14, 59-62. https://doi.org/10.1097/LGT.0b013e3181b0f8f3

[29] Yang, J., Guo, Q., Yang, Y., Zhang, J., Lang, J. and Shi, H. (2012) Primary Vulva Ewing Sarcoma/Primitive Neuroectodermal Tumor: A Report of One Case and Review of the Literature. Journal of Pediatric and Adolescent Gynecology, 25, 93-97. https://doi.org/10.1016/j.jpag.2012.03.005 